\title{
Effect of Audio-Visual Aided Instruction on Junior Secondary School Students' Interest and Achievement in Fraction in Nasarawa State, Nigeria
}

\author{
Pindar, G. M. and Agu, P. A.* \\ Department of Science, Technology and Mathematics Education, \\ Faculty of Education, Nasarawa State University, Keffi, Nasarawa State, Nigeria \\ *Corresponding author details: Assoc. Prof, P. A. Agu, ashlameagu@yahoo.com
}

\begin{abstract}
The study examined the Effect of Audio-Visual Aided Instruction on Junior Secondary Students' Interest and Achievement in Fraction in Nasarawa State. The study is a quasi-experimental research in which pretest-posttest was used. Purposive sampling technique was employed to select the schools that were used for this research work. It was purposive in the sense that only schools having functional ICT units that were used for the study. The population was made up of 918 JS1 (504 males and 414 females). Two intact classes drawn from two government schools were selected for this research work. One class was used as experimental group while the other as control group. A validated 40 items Fraction Achievement Test (FAT) and 20 items Fraction Interest Scale (FIS) were constructed by the researchers as instruments for the study. Data were collected and analyzed to answer the research questions using mean and standard deviation while the hypotheses were tested at 0.05 level of significance using ANCOVA. It was found that students taught fraction using audio-visual aided instruction achieved higher than their counterparts who were taught using conventional method. Students expressed higher interest in fraction when taught using audio-visual aided instruction. The study therefore recommends that mathematics teachers should be encouraged to adopt the use of audio-visual aided instruction in teaching and learning of fractions in mathematics to improve students' interest and achievement in the subject.
\end{abstract}

Keywords: Effect; audio-visual; interest; achievement; fraction; conventional method

\section{INTRODUCTION}

Mathematics has been seen as a very important means of developing the society. It is the study of topics such as quantity (number), structure, space and change. There is a wide range of views among mathematicians and philosophers as to the exact scope and definition of mathematics. Mathematics is the science of numbers and their operations, interactions, combinations, generalization and abstractions and of space configurations and their structure, measurement, transformation and generalization. Algebra, arithmetic, calculus, geometry, and trigonometry are all branches of mathematics. The knowledge of mathematics in classroom has become a concern for educators. Relentlessly, educators have come up with several teaching methods such as lecture method, cooperative learning (learning in groups) and active or activity-based learning (engaging students actively in their own learning process) emerged as better methods of teaching and learning. However, in this computer era, problems associated with teaching and learning still persist as shown in the nation's poor results (Telima, 2011). This is why Abakpa and Iji (2011) stressed that mathematics educators should continue to intensify efforts in proffering solutions to the teaching and learning of mathematics.

Many students see fraction as a difficult topic, these could result in mass failure of mathematics in the West African Senior Secondary Certificate Examination (WASSCE), National Examination Council (NECO), Unified Tertiary Matriculation Examination (UTME) and other qualifying examinations. The statistics of mass failure churned out in qualifying examinations across the country can attest to this fact.
It is almost impossible to go a whole day without using fractions, for example, in telling time, splitting bills, halving recipes, planning meals, shopping sales, counting change, fractions come up so often that we might not notice them. They are the most important concepts to learn for success in mathematics. The knowledge of fraction is very important to students as it exposes them to some areas in mathematics which is required in higher education. For example, in algebra, the slope of a line is expressed in fractional form, and students work with fractions that have variables in the numerator and/or denominator (rational expressions). In geometry, students work with trigonometry ratios (sine, cosine, tangent, etc) and similar figures, which also require the ability to work with fractions. Even in science classes, such as chemistry and physics, students need to be able to use their knowledge of fractions to convert units to measure. In fact, fractions seem to be the single greatest predictor of high school mathematics achievement, independent of other types of mathematical knowledge, general intellectual ability, working memory, family income and education. (Singler, Duncan, Davis-Kean, Dunkworth, Claessens, Engel, Susperreguy \& Chen, 2012).

Audio-visual aids are those instructional devices which are used in the classroom to encourage learning and make it easier and interesting. Materials such as carts, maps, models, film strip, projectors, radio, and television are called instructional aides (Viswanath \& Mahaeswara, 2016). Audio-visual aids provide the learners with realistic experience which capture their attention and help in the understanding of historical phenomena. They appeal to the mind through the visual and auditory senses (Samreen \& Sufiana, 2012). Audio-visual Aided Instruction is an 
instruction where particular attention is paid to the audio and visual presentation of the material with the goal of improving comprehension and retention. Children learn best by observing and copying the behaviours of adults. It is therefore evident that learning is more effective when sensory experiences are stimulated. These include pictures, slides, radios, videos and other audio-visual tools. Audio-visual aids have grown exponentially with several multimedia such as educational series, You-Tube, and other online materials. The goal of audio-visual aids is to enhance teachers' ability to present the lesson in simple, effective and easy to understand for the students. Audiovisual materials make learning more permanent since students use more than one sense. In this research work, audio-visual aids used include; pictures, videos, charts, computer, laptop, projector and white board.

Achievement is an act of accomplishing something, especially by superior ability, special effort and great courage. A strong foundation in fraction is particularly important as it allows children to better acquire new and advanced knowledge in mathematics which contributes to successful participation in tertiary education and an increasing knowledge based society. For students, learning fraction is integral to a great many aspects of their lives. These aspects include time, money and budgeting, being fair to others, claiming rights, recognizing and generalizing from symbols and patterns, using technology, interpreting information, thinking systematically and creatively, making things, and solving problems. Many children and adults struggle with fractions. For example, in a test on fraction given to JS1 students of a certain school in Nasarawa State, only $49 \%$ of the students were able to correctly order $2 / 7$, $1 / 2$ and 5/9 from least to greatest. On another trial test carried out, only $55 \%$ correctly solved a simple word problem involving fraction division. Despite fraction instruction beginning in elementary school, many people fail to gain a firm understanding of fractions and harbor misconception through high school and college. This is a serious problem, because understanding fractions is a foundational mathematical skill. Early knowledge in fraction strongly predicts later achievement in mathematics even after children's Intelligence Quotient (IQ), reading comprehension, working memory, whole number arithmetic knowledge, race, ethnicity, parental education, and income are statistically controlled. In a study involving 80 mathematics teachers, it was identified that lack of understanding fraction is one of the two largest problems hindering students' learning of algebra. This could also be applicable to other branches of mathematics which could be the result of mass failure in mathematics examinations.

Interest in mathematics relates to people's intrinsic motivation to acquire new mathematical skills. The association between interest in a subject and achievement is often viewed as complex. Some studies, such as that of Lee, Lee \& Bong (2014) found that stable interest in particular academic subjects predict achievement in those subjects but, indirectly through the mediating effects of self-regulation. In the context of learning mathematics, interest has been viewed as students' motivation for engaging in mathematics activities. Individual differences in the aspect of motivation to learn mathematics seem to emerge as early as primary school and such factors could predict future learning. If a student develops a high sense of interest or is motivated towards a particular subject, it could be a plus for him/her because achievement in the subject would be high.

Conventional method as used in this study refers to the traditional way of teaching wherein most of the time, lecture method is used. This method of teaching is textbook centered, teacher dominant, exam-oriented. The emphasis is mainly in remembering and producing facts, principles and theories. The conventional method used for this study is the demonstration method in which the topic of consideration fits into. The demonstration method is a process of teaching someone in a step-by-step process. Demonstration means any planned performance of an occupation skill, scientific principle or experiment. Using demonstration gives a good performance and explains each step or process as one proceeds. It is against this backdrop that this study investigated the effect of audiovisual aided instruction on junior secondary school students' interest and achievement in fraction in Nasarawa State.

\section{STATEMENT OF THE PROBLEM}

Mathematics is a compulsory subject and one of the core subjects at the secondary level of education. This is because of the role it plays in any country's scientific and technological development. Students' lack of interest and poor academic achievement in WASSCE mathematics examination has become a source of concern to all stakeholders. Researchers claim that the beginning of mathematics anxiety in students can often be traced to the day they enter school and are introduced to fractions. Fractions are assumed to be difficult to learn. Understanding the difficulties associated in learning fractions seems absolutely crucial as it could lead to reduction in mathematics anxiety and increase students' interest in mathematics. This has strong implications for the study of science and technical subjects at institutions of higher learning. In a bid to improve students' learning outcome in mathematics, this study investigated the effect of audio-visual aided instruction on junior secondary school students' interest and achievement in fraction in Nasarawa State, Nigeria.

\section{RESEARCH QUESTIONS}

The following research questions guided the study:

i. What are the mean interest ratings of students taught fraction using audio-visual aided instruction and those taught using conventional (Demonstration) method?

ii. What are the mean achievement scores of students taught fraction using audio-visual aided instruction and those taught using conventional (demonstration) method?

\section{HYPOTHESES}

The following null hypotheses were formulated and tested at 0.05 level of significance.

Ho1: There is no significant difference in the mean interest scores of students taught fraction using audio-visual aided instruction and those taught using the conventional (demonstration) method.

Ho2: There is no significant difference in the mean achievement scores of students taught fraction using audio-visual aided instruction and those taught using the conventional (demonstration) method.

\section{METHODOLOGY}

The study adopted quasi-experimental research design in which a non- randomized Pretest, Posttest design was used. The design was chosen because it was not possible to have subjects randomly assigned to groups. It was also considered appropriate for this study because intact classes were used instead of randomly composed samples. In the study, one intact class of 
students was assigned to experimental group which received treatment while the other class served as the control group which received no treatment. The experimental group was taught using audio-visual aided instruction while the control group was taught using the demonstration method. The target population comprised Junior Secondary One (JS1) students in six government secondary schools in Lafia Inspectorate Education Area of Nasarawa State. The population consists of 918 Junior Secondary One students from government secondary schools in Lafia inspectorate Education Area made up of 504 males and 414 females as at 2018/2019 academic session. The sample size for the study was 80 JS1 students drawn from two intact classes from two schools in Lafia Inspectorate Area. To obtain the sample, purposive sampling technique was adopted where two government schools out of six in Lafia Education area were randomly selected based on the fact that the researcher required schools that have functional computers. The sample of the study consisted of 45 males and 35 females making a total of 80 students. The instruments for data collection included Fraction Achievement Test (FAT) and Fraction Interest Scale (FIS). The FAT was constructed by the researcher. The items generated covered the basic concepts of fraction taught in JS1. The FAT consisted of items from the subheading under fraction which include proper fraction, improper fraction, mixed fraction, equivalent fraction. The FAT was used as pre-test to assess the students' level of understanding the concept of fraction before the treatment commenced. The same FAT items were used for the post-test to determine students' achievement in fraction for both experimental and control groups. The students were required to choose either option a, b, or c from each of the 40 test items constructed from the topics listed above. The FIS was adapted from that of Maigana (2016) who initially developed interest rating items to measure students' interest in Geometry. The items of Maigana's geometric interest scale (GIS) were reconstructed to follow the content of Fraction under this study. The FIS had two sections namely, sections A which solicited the demographic information about the respondents while section B listed 20 items on students' interest in fraction and were scored based on the rating scale of
Strongly Agree $(S A)=4$, Agree $(A)=3$, Disagree $(D)=2$, and Strongly Disagree $(\mathrm{SD})=1$. FAT and FIS went through face and content validity by two experts, one from Mathematics Education background while the other from Measurement and Evaluation. They were asked to determine the appropriateness or otherwise of the instruments in achieving the purpose of the study. Recommendations received from the experts were considered in constructing the final draft of the instruments. A table of specification was constructed for the FAT to ensure a fair spread of the items. The table of specifications was given to the experts along with the instruments for scrutiny and necessary comments. A trial-testing was carried out to determine the reliability of the FAT. 30 JS1 students from two schools in Lafia Education Area Inspectorate which were part of the population but not part of the study sample were used for the trial test. The result of the trial test was used to compute the reliability of FAT and FIS. The FAT was subjected to item analysis test and was found to have a difficulty index and discriminating power of 0.40 and 0.15 respectively. Split half method was used for the reliability test.

The reliability coefficient was calculated using the Spearman Broun's formula where a value of 0.97 was obtained. The reliability coefficient for the FIS was computed using Cronbach Alpha. The result yielded an index of 0.82 which were considered reliable. Before the treatment, the two groups were pre-tested using FAT and FIS to ascertain the entry level of the students. After this, the experimental group was taught using the audio-visual aided instruction while the control group was taught using the demonstration method. The lessons were taught to both groups using the two methods over four weeks including the administration of the instruments. After the treatment, the two groups were given a post-test (same FAT and FIS) to determine the effect of the treatment or lack of it on the students. The scores obtained from the data collected were used for analysis. The research questions were answered using mean and standard deviation while ANCOVA was used to test the hypotheses at 0.05 level of significance.

\section{RESULTS}

\section{Research Question 1}

What are the mean interest ratings of students taught fraction using audio-visual aided instruction and those taught using conventional (demonstration) method?

The data that answered this research question is presented on table 1.

TABLE 1: Mean Interest Scores and students Deviation in the Experimental and Control Groups

\begin{tabular}{lccccc}
\hline Teaching Method & Type of test & No of Students & Mean & $\begin{array}{c}\text { Standard } \\
\text { Deviation }\end{array}$ & Mean Gain \\
\hline $\begin{array}{l}\text { Audio Visual Aided } \\
\text { material }\end{array}$ & $\begin{array}{c}\text { Pre-interest } \\
\text { Post-interest }\end{array}$ & 45 & 53.68 & 4.942 & 7.65 \\
$\begin{array}{l}\text { Conventional } \\
\text { method }\end{array}$ & Pre-interest & 45 & 61.33 & 7.191 & \\
\hline
\end{tabular}

Table 1 shows the mean interest scores and standard deviations of experimental and control groups. It could be seen that the mean interest scores of students taught using audio-visual aided instruction is 53.68 and 61.33 in preinterest and post-interest, respectively and standard deviation of 4.942 and 7.191 in interest scores while students who were taught using the conventional method had the mean interest scores of 54.24 and 62.55 in pre-interest and post-interest respectively. It was observed too that the mean gain interest scores for the experimental and control groups were 7.65 and 8.31 respectively. This implies that students who were taught using the conventional method of demonstration showed higher interest in fraction. 
Hypothesis 1

There is no significant difference in the mean interest scores of students taught fraction using audio-visual aided instruction and those taught using the conventional (demonstration) method.

The result of the test is shown on table 2 .

TABLE 2: One-way ANCOVA Result on Students' Interest in Fraction Taught Using Audio-visual Aided Instruction and Demonstration Method

\begin{tabular}{lcccccc}
\hline \multicolumn{1}{c}{ Source } & $\begin{array}{c}\text { Type III sum of } \\
\text { Squares }\end{array}$ & df & Mean Square & F & Sig & Results \\
\hline Corrected model & 139.014 & 2 & 69.507 & 1.302 & .278 & NS \\
Intercept & 2327.510 & 1 & 2327.510 & 43.597 & .000 & S \\
Pre-interest & 18.964 & 1 & 18.964 & .355 & .553 & NS \\
Group & 108.486 & 1 & 108.486 & 2.032 & .158 & NS \\
Error & 4110.786 & 77 & 53.387 & & & \\
Total & 317250.000 & 80 & & & & \\
Corrected total & 4249.800 & 79 & & & & \\
\hline
\end{tabular}

$\mathrm{S}=$ Significant at $\mathrm{P}<0.05$

Table 2 shows the summary of the one-way ANCOVA of students' interest scores in fraction. The result revealed that the noted difference between the mean interest score of students' taught using audio-visual aided instruction and those taught using the conventional method is not significant at 0.05 alpha level. This is from the fact that $F_{(1,77)}=$ 2.032 and $P=0.158>\alpha=0.05$. The null hypothesis was therefore not rejected. That is to say there is no significant difference in the mean interest rates of students taught fraction using audio-visual aided instruction and those taught using the conventional method.

\section{Research Question 2}

What are the mean achievement scores of students taught fraction using audio-visual aided instruction and those taught using the conventional (demonstration) method?

The data that answered this research question is presented on table 3.

TABLE 3: Mean Scores and Standard Deviations of Students' Achievement in Experimental and Control Groups

\begin{tabular}{lccccc}
\hline Teaching Method & Type of test & No of Students & Mean & $\begin{array}{c}\text { Standard } \\
\text { Deviation }\end{array}$ & Mean Gain \\
\hline $\begin{array}{l}\text { Audio Visual Aided } \\
\text { material }\end{array}$ & Pre-interest & 45 & 21.10 & 5.611 & 16.28 \\
& Post-interest & 35 & 17.38 & 7.386 & \\
$\begin{array}{l}\text { Conventional } \\
\text { method }\end{array}$ & Pre-interest & 45 & & & \\
\end{tabular}

Table 3 shows the mean scores and standard deviations of students' achievement in experimental and control groups. It could be observed that the mean scores of students taught using audio-visual aided instruction is 21.10 and 37.38 in pretest and posttest respectively and standard deviation of 5.611 and 7.386 in achievement test. Students who were taught using the conventional method had the mean score of 35.34 and 49.88 in pretest and posttest respectively and standard deviation of 8.028 and 7.533 in achievement test. It was also observed that the mean gain scores for the experimental and control groups are 16.28 and 14.54 respectively. This implies that students taught using audio-visual aided instruction performed better than those taught using conventional method.

\section{Hypothesis 2}

There is no significant difference in the mean achievement scores of students taught fraction using audio-visual aided instruction and those taught using the conventional method.

The result of the test is shown in table 4.

TABLE 4: One-way ANCOVA Result on Students' Mean Achievement Scores in Fraction Taught Using Audio-visual Aided Instruction and Demonstration Method

\begin{tabular}{lcccccc}
\hline \multicolumn{1}{c}{ Source } & $\begin{array}{c}\text { Type III sum of } \\
\text { Squares }\end{array}$ & df & Mean Square & F & Sig & Results \\
\hline Corrected model & 12511.689 & 2 & 6255.845 & 111.271 & .000 & 5 \\
Intercept & 7764.127 & 1 & 7764.127 & 138.099 & .000 & 5 \\
Pretest & 11.689 & 1 & 11.689 & .209 & .650 & NS \\
Method & 2651.161 & 1 & 2651.161 & 47.156 & .000 & S \\
Error & 4329.061 & 77 & 56.222 & & & \\
Total & 215842.000 & 80 & & & & \\
Corrected total & 16840.750 & 79 & & & & \\
\hline
\end{tabular}

Significant at $\mathrm{P}<0.05$

Table 4 shows the result of one-way ANCOVA on student achievement in fraction. The results revealed that the noted difference in the mean achievement scores of those taught fraction with audio-visual aided instruction and those taught with the conventional method is significant at 0.05 alpha levels. This is from the fact that $\mathrm{F}_{(1,77)}=47.156$ and $\mathrm{p}$ $=0.000<\alpha=0.05$. The null hypothesis was therefore, rejected meaning that there is significant difference in the 
mean achievement scores of students taught fraction using audio-visual aided instructions and those taught using the conventional method. This implies that students achieved better when taught using the Audio-visual Aided Instruction than when taught using the conventional method.

\section{DISCUSSION OF FINDINGS}

The discussion of the results was made based on the findings of the research obtained through the analysis of data. The mean achievement scores of students taught using audio-visual aided instruction as shown was higher than the mean achievement scores of students taught using conventional method. This shows that students who were taught using the audio-visual aided instruction performed better than those taught using the conventional method. This finding supports that of previous researchers such as Nelson, Isaac, and Osafo (2012); Abdullahi and Danladi (2017); Ma'aji, Hassan, Usman, Ibrahim, Musa, and Ajiya (2017) who found that students exposed to audio-visual aided instruction performed better than their counterparts who were exposed to conventional method. This shows that teaching fraction using the audio-visual aided instruction would better enable students to proceed to abstract reasoning and improve performance in mathematics. This is because Audio-visual aids presents subjects/content in a more memorable and interesting way than through textbooks or a single medium.

The mean interest rating of students taught fraction using audio-visual aided instruction and those taught using conventional method as observed in the mean gain of those taught with the conventional method was slightly above those taught with the audio-visual aided instruction. The result of the one-way ANCOVA showed a significant difference in students' interest when taught fraction using audio-visual aided instruction and those taught using conventional method. These findings are in consonance with that of Odo (2015), Lawal and Ibrahim (2016), Ma'aji, Hassan, Usman, Ibrahim, Musa and Ajiya (2017) who found that students have higher interest in integrated science, biology, and mathematics when taught using audio-visual aided instruction compared to those using the conventional method. This implies that teaching fraction using audio-visual aided instruction aroused students' interest to learn and work hard in order not to avoid answering questions on fraction during examinations. If students develop high sense of interest or are motivated towards a particular subject, it would be a plus for them because achievement in the subject would be high.

\section{CONCLUSION}

Based on the results of this study, it was concluded that audio-visual aided instruction is more effective in teaching fraction than conventional method. Students taught using audio-visual aided instruction performed better than those taught without it. Students expressed more interest in learning fraction using the audio-visual aided instruction than using the conventional method.

\section{RECOMMENDATIONS}

From the findings of this study, the following recommendations were made:

1. Mathematics teachers should be encouraged to adopt the use of audio-visual aided instruction in teaching and learning of fractions in mathematics.

2. Mathematics teachers in secondary schools should be sensitized through seminars and workshops by Mathematics Association of Nigeria (MAN) on the use of audio-visual aided instruction for teaching fractions in mathematics.

\section{REFERENCES}

[1]. Abakpa, B. \& Iji, C. (2011). Effect of mastery learning approach on senior secondary school students' achievement in geometry. Journal of the Science Teachers' Association of Nigeria 46 (1), 165-176.

[2]. Abdullahi, S. \& Danladi, A. A., (2017). Effect of multimedia instructional method on secondary schools students' achievement in economics in Nasarawa State, Nigeria. Journal of Science, Technology and Education (JSTE) vol 1, No. 1, pp 01-09.

[3]. Lawal, E. T. \& Ibrahim, S. T., (2016). Impact of multimedia instruction on biology students academic performance and interest. Journal of Information, Education Science and Technology (2) pp 3.

[4]. Lee, W., Lee, M. \& Bong, M. (2014). Testing interest and self efficacy as predictor of academic selfregulation and achievement. Contemporary Educational Psychology 39(2).

[5]. Ma'aji, A. S., Hassan, A. M., Usman, G. A., Ibrahim, D.; Musa, M. H. \& Ajiya, C. (2017). Effect of multimedia on junior secondary school students' achievement, interest, and retention in basic science and technology in Niger state. Journal of 3rd International Conference of School of Science and Technology Education (SSTE). FUT, Minna. Pp 233-239.

[6]. Maigana, B. (2016). Effect of computer assisted instruction on senior secondary students' achievement and interest in geometry in federal capital territory Abuja. Unpublished M. Ed dissertation. Nasarawa state university, Keffi.

[7]. Nelson, R. Q., Isaac, B., \& Osafo, D. K. (2012). Impact of audio-visual aids on senior high school students' achievement in physics. International Journal of Physics and Chemistry Education 2012; 4(1): 46-54.

[8]. Odo, C. 0. (2015). Effects of audio-visual aided instruction on students' achievement in Lafia educational zone of Nasarawa state. Unpublished M. Ed dissertation. National Open University of Nigeria.

[9]. Samreen, A. \& Sufiana, K. (2012). Use of audio-visual aids for effective teaching of biology in secondary schools level. Samreen Akram et al./ Elixir leadership Mgmt. 50(2012) 10597-10605 available online at www.elixirjournal.org

[10].Siegler, R. S., Duncan, G. J., Davis-Kean, P. E., Duckworth, K., Claessens, A., \& Engel, M.,(2012). Early predictors of high school mathematics achievement. Psychological Science. 23: 691-697.

[11].Telima, A., (2011). Problems of teaching and learning of geometry in secondary schools in River state. Nigeria,Retrieved from $h t t p: / / c i t e ~ s e e r x . p s u . e d u / s u m m a r y ~ d o i: 10$

[12].Viswanath, P. C. \& Maheswara, R. C. (2016). The role of audio-visual aids in teaching \& learning english language. International Journal of Science Research (5) 4, 2016 